\title{
DA EVOLUÇÃO DO DIREITO A SER DEIXADO EM PAZ À PROTEÇÃO DOS DADOS PESSOAIS
}

Têmis Limberger

\section{RESUMO}

O fenômeno informático permite um fluxo de dados pessoais sem fronteiras. Nesse contexto, o uso indevido da informática se constitui numa ameaça ao direito à intimidade, tendo em vista a possibilidade de violação, divulgação e de comercialização dos dados (tratados como uma nova mercadoria). E importante assegurar proteção aos direitos não só na esfera pública, mas sobretudo no âmbito privado, uma vez que, hoje, as relações jurídicas, majoritariamente, aí se situam. Essa problemática recebe atenção de Espanha e de Portugal, que, em sede constitucional, dispõem a respeito da informática. Recentemente, o Tratado de Lisboa, reconheceu a proteção de dados pessoais como direito fundamental. No Brasil, há a necessidade de legislação específica, enquanto isto não ocorre, é possível construir proteção jurídica, a partir da Constituição. O grande desafio, atualmente, é proteger a intimidade do cidadão frente aos dados informatizados, no mundo globalizado.

Palavras-chave: Constituição. Direitos Fundamentais. Fenômeno Informático. Globalização. Proteção de Dados Pessoais.

\section{INTRODUÇÃO}

Os dados pessoais têm um valor na sociedade atual voltada ao consumo, por isto é necessário que haja uma preocupação dos juristas com este tema. $O$ mundo globalizado apresenta problemas que envolvem diferentes países e como tal, demanda soluções no âmbito nacional e internacional. Hoje se assiste a um incremento tecnológico capaz de lesar os direitos fundamentais. Assim, os correios eletrônicos não desejados, denominados spams, representam aproximadamente $2 / 3$ do tráfego mundial de mensagens e provocam o desperdício de tempo e dinheiro. Um estudo realizado pela União Européia ${ }^{1}$ revelou que a circulação diária de lixo eletrônico por e-mail custa $\bigcup \$ 9,36$ bilhões para os internautas, a cada ano. Considerando que há aproximadamente 500 milhões de internautas no mundo, o spam tem um custo individual de U\$20,00.

Desta forma, instrumentos que podem ser utilizados para armazenar uma infinidade de conhecimento, bem como para transmiti-lo de uma maneira célere são desvirtuados pelos spammers ou até pelo uso de práticas criminosas pelos hackers. Destarte, além do elevado custo econômico e desperdício de tempo que 
estas práticas provocam, a lesão ao direito à intimidade, resta evidente. Por isso, as questões referentes às novas tecnologias e os direitos fundamentais por afetarem a distintos países, passam por soluções de regulação na órbita jurídica internacional e nacional.

Das situações da vida cotidiana surgem possibilidades de interferência na intimidade, como as videocâmeras de segurança (colocadas em edifícios públicos e privados, especialmente em bancos e lojas) ou de controle da atividade no local de trabalho, os programas de televisão interativos e os rastreadores em Internet. Também podem ser considerados os bancos de dados pessoais, voltados na maioria das vezes ao consumo. Percebe-se, desse modo, que o homem vigiado constantemente pelo Grande Irmão de George Orwell ${ }^{2}$ não é mais ficção, mas se converteu em realidade. Por isso, é atual a lição do jusfilósofo Norberto Bobbio $^{3}$,quando assevera: o desafio principal dos direitos do homem, atualmente, não é o de justificá-los, mas sim o de protegê-los. Este é um problema que ultrapassa a filosofia e entra no âmbito da política. Garantir a efetividade dos direitos fundamentais, em geral, e da intimidade diante do fenômeno informático, em particular, é a grande questão enfrentada pelos juristas, considerando as invasões que se costumam ocorrer nos bancos de dados.

\section{A IMPORTÂNCIA DOS DIREITOS FUNDAMENTAIS FRENTE ÀS NOVAS TECNOLOGIAS: OS PERFIS DE CONSUMO}

A necessidade de proteger o cidadão juridicamente se origina no fato de que os dados possuem um conteúdo econômico, pela possibilidade de sua comercialização. Devido às novas técnicas da informática, a intimidade adquire outro conteúdo, uma vez que se tenta resguardar o cidadão com relação aos dados informatizados. Um cadastro pode armazenar um número quase ilimitado de informação. Assim, o indivíduo que confia seus dados deve contar com a tutela jurídica para que estes sejam utilizados corretamente, seja em entidades públicas ou privadas.

Os dados traduzem aspectos da personalidade e revelam comportamentos e preferências, permitindo até traçar um perfil psicológico dos indivíduos. Dessa maneira, podem-se detectar hábitos de consumo, que têm grande importância para a propaganda e o comércio. É possível, por meio dessas informações, produzir uma imagem total e pormenorizada da pessoa, que se poderia denominar de traços de personalidade, inclusive na esfera da intimidade. O cidadão converte-se no denominado "homem de cristal". ${ }^{4}$

As novas tecnologias tornam a informação uma riqueza fundamental da sociedade. Os programas interativos criam uma nova mercadoria. $O$ sujeito fornece os dados de uma maneira súbita e espontânea e, por conseguinte, depois que estes são armazenados, esquece-se ${ }^{5}$ de que os relatou. Por isso, é um desafio oferecer proteção à intimidade com relação a esses serviços. 
Os meios de comunicação interativos modificam a capacidade de coleta de dados, instituindo uma comunicação eletrônica contínua e direta entre os gestores dos novos serviços e os usuários. Portanto, é possível não só um controle do comportamento dos usuários, mas também um conhecimento mais estreito de seus costumes, inclinações, interesses e gostos. Disso deriva a possibilidade de toda uma série de empregos secundários dos dados recolhidos.

Quanto mais sofisticados são os serviços oferecidos, maior é a quota de informação pessoal deixada pelo indivíduo nas mãos do provedor do serviço, e tal informação pode ser utilizada para a criação de perfis individuais e coletivos de usuários. Além disso, quanto mais extensa a rede dos serviços, mais crescem as possibilidades de interconexão entre os cadastros ou bancos de dados e a disseminação internacional da informação recolhida. ${ }^{6}$

Por fim, a seguinte notícia ilustra o que aqui se pretende desenvolver: "Loja filma todas as reações de seus consumidores". ${ }^{7}$ Diante da constatação de que as pessoas omitem ou alteram informações quando são questionadas em pesquisas de consumo, determinada loja de departamentos ${ }^{8}$ resolveu usar centenas de câmeras de circuito interno de TV, microfones ultra-sensíveis e uma central de última geração na qual se concentram monitores. Os consumidores são filmados em todas as suas reações: quanto tempo ficam paradas diante de um produto, qual o cartaz de ofertas que foi mais observado, quais são as expressões faciais diante das mercadorias e quais são as reações diante dos preços. O consumidor é observado como um peixe num aquário. Como advertência aos que entram na loja, foi colocado um cartaz com os seguintes dizeres: "Este lugar está sendo filmado para testes; se isso o incomoda, volte quando este aviso não estiver aqui". ${ }^{9}$ Ressalte-se que o cartaz está quase sempre no local. Segundo as leis do Estado, os proprietários podem filmar e gravar o quanto quiserem, desde que fiquem longe dos provadores.

Até que ponto um pequeno cartaz é suficiente para advertir os consumidores? O consentimento para a captação dos dados está atendido? Saliente-se que, outras vezes, pode haver câmeras em locais sob o pretexto de vigilância que, na realidade, servem para observar perfis de consumo, em um completo desvio de finalidade.

Os publicitários perceberam que num questionário o consumidor pode alterar as informações, seja sonegando às que entender inadequadas, seja respondendo perguntas de forma inverídica. Assim, com as filmagens, a privacidade do consumidor está sendo fortemente invadida, visto que é mais devassada do que se ele preenchesse um formulário.

A necessidade de proteger o cidadão juridicamente se origina no valor econômico que os dados possuem, ou seja, pela possibilidade de sua comercialização. Diante das novas técnicas da informática, a intimidade adquire outro conteúdo: visa-se resguardar o cidadão com relação aos dados informatizados. Um arquivo informatizado pode guardar um número quase ilimitado 
de informações. Assim, o indivíduo que confia seus dados deve contar com a tutela jurídica para que estes sejam utilizados corretamente, quer se trate de um organismo público ou privado.

As novas tecnologias convertem a informação em uma riqueza fundamental da sociedade. A função da intimidade no âmbito informático não é apenas proteger a esfera privada da personalidade, garantindo que o indivíduo não seja incomodado devido à má utilização de seus dados. Pretende-se evitar, outrossim, que o cidadão seja transformado em números ${ }^{10}$, tratado como se fosse uma mercadoria, sem a consideração de seus aspectos subjetivos.

É significativo que cada vez com maior freqüência sejam realizadas sondagens de opinião e perfis de consumo. Por isso, constitui um desafio oferecer proteção à intimidade do cidadão com relação a esses serviços.

\section{O FENÔMENO INFORMÁTICO E O ESTADO NO CONTEXTO ATUAL}

O denominado constitucionalismo jovem europeu, que ocorre em Portugal depois da ditadura de Salazar, que culmina com a Constituição de 1976, e a Constituição Espanhola de 1978, depois de Franco são as primeiras Cartas que prevêem a utilização da informática e o resguardo dos direitos fundamentais. A primazia coube à Constituição de Portugal, que foi o primeiro texto constitucional europeu a disciplinar de forma específica a proteção de dados pessoais.

Nesse contexto, a Constituição do Brasil de 1988 surge depois da ditadura militar e se inspira nestas normas constitucionais de vanguarda. Como exemplos de contribuição podem ser citados os institutos da inconstitucionalidade por omissão ${ }^{11}$, com inspiração na Constituição da República Portuguesa (CRP), e o habeas-data $^{12}$ da Constituição Espanhola (CE), porém inexiste um dispositivo constitucional específico para violação dos dados pessoais, no direito brasileiro.

O artigo 35 da CRP (que originalmente se referia a dados mecanográficos) sofreu algumas alterações para incluir a utilização da informática e os ficheiros manuais $^{13}$. Catarina Sarmento e Castro posiciona-se no sentido de que a proteção constitucional vai além da epígrafe "utilização da informática", "este é um direito de proteção da informação pessoal face ao uso da informática, mas também em relação a outros meios: os dados pessoais contidos em ficheiros manuais devem gozar de idêntica proteção"14.

É de se destacar a posição mais de vanguarda, no sentido de reconhecer o direito à proteção da informação pessoal e não somente a autodeterminação informativa.

O enfrentamento da questão das novas tecnologias também ocorreu por parte dos espanhóis, pelo artigo 18.4 da CE. A quantidade de informações que podem ser armazenadas e transmitidas é de tal magnitude que exige o 
estabelecimento de soluções para os problemas que podem resultar da relação entre informática e intimidade. ${ }^{15}$

Assim, além do caráter subjetivo do cidadão (de defesa do direito da intimidade diante da informática), há o caráter objetivo ${ }^{16}$ do mandato ao legislador, que ocorre na proteção do direito, muitas vezes com determinação de elaboração legislativa que deve ser concretizada. ${ }^{17} \mathrm{~A}$ defesa do direito fundamental é a da própria Constituição, realizada muitas vezes com a ponderação de direitos na tarefa de interpretação pelo TC.

Os direitos no Estado Social possuem um cunho positivo, que é o aspecto prestacional de demanda com relação aos poderes públicos. A intimidade, que até então se restringia ao direito a não ser molestado ${ }^{18}$ (aspecto negativo), típico do Estado Liberal, resolvido com a não intervenção da esfera pública na seara particular, começa a demandar ações concretas, como o consentimento para a coleta de dados, com especial ênfase para os dados sensíveis. Estes devem ser corretamente armazenados e por um prazo delimitado, bem como utilizados para os fins a que foram recolhidos (e que somente haja repasse nas hipóteses legais). São também exemplos dessas prestações concretas o direito de informação, acesso, retificação e cancelamento dos dados.

$\mathrm{Na}$ atualidade, os típicos elementos ${ }^{19}$ referenciais de Estado não subsistem. A Internet muda o clássico conceito de território e a noção de soberania também sofre transformações. Os acordos comerciais entre as nações estão na ordem do dia. A Europa desenvolveu um mercado comum que originou a União Européia ${ }^{20}$. $O$ Estado perde a soberania em proveito de instâncias superiores, como os pactos internacionais e os acordos políticos regionais. Há diminuição no papel do Estado e dialética constante entre o global e o regional. Durante séculos houve a convicção de que não poderia haver regulação social senão pelo direito do Estado, idéia hoje que está superada. Os fluxos de dados não ocorrem somente nas fronteiras de um país, por isso a necessidade da DC 95/46, que colabora para a resolução dos problemas nos países comunitários, mas ainda não contempla os demais Estados. O comércio e o intercâmbio de informação e de dados são necessários, são uma demanda da sociedade atual, e por isso impõe-se a tutela dos direitos fundamentais, com a denominada globalização. ${ }^{21}$

O pluralismo contemporâneo é oriundo da fragmentação das soberanias, manifestada na noção de supranacionalidade que culminará provavelmente com a Carta de Direitos Fundamentais da União Européia. É a denominada "europeização do direito constitucional". ${ }^{22}$ Daí decorre a importância de estabelecer um marco padrão para todos os países comunitários europeus, no tocante a um catálogo mínimo de direitos.

A superação do jusnaturalismo e as insuficiências do positivismo abriram caminho ao pós-positivismo, o qual atribui um papel importante à normatividade dos princípios. O constitucionalismo moderno se reaproxima dos valores, em especial da ética no direito. ${ }^{23}$ De longo tempo os princípios estão no direito, a 
novidade é sua estatuição constitucional.

Os princípios constitucionais fazem uma síntese de valores no ordenamento jurídico e têm como funções principais, conferir unidade ao sistema e auxiliar a atividade de interpretação. Nas palavras de Lênio Streck,

é a partir da superação da crise paradigmática do Direito (crise de modelos de Direito e de Estado) é que poderemos dar um sentido eficacial à Constituição, inserida no novo modelo de cunho transformador que é o Estado Democrático de Direito. Ao lado disto, é imprescindível uma nova hermenêutica jurídica, que possibilite ao operador do Direito a compreensão da problemática jurídico social. ${ }^{24}$

Daí decorre uma mudança de postura na solução de diversas questões jurídicas e in casu, do fenômeno informático que atua com extrema velocidade, desafiando o ritmo mais lento com o qual atuam os operadores do direito.

É possível pensar nos direitos humanos como uma idéia agregada à democracia. Assim, no dizer de Canotilho ${ }^{25}$, o Estado Democrático de Direito exige os direitos fundamentais, e os direitos fundamentais exigem o Estado Democrático de Direito. A democracia tenta superar o confronto dos direitos fundamentais pela ponderação jurisprudencial.

A aplicação dos princípios ocorre com a ponderação de valores ou interesses, como, por exemplo, a intimidade e o interesse público, a prevalência de um em detrimento de outro, a ser analisada caso a caso pela jurisprudência, bem como a problemática de conteúdo e limites próprios dos direitos fundamentais com sua forte carga axiológica. Assim, a ponderação dos direitos fundamentais e a dignidade da pessoa são basilares no direito constitucional pós-moderno. Os direitos fundamentais como exigência e concretização do princípio da dignidade humana. ${ }^{26}$

Então, poder-se-ia propugnar uma construção ou uma leitura dos direitos fundamentais com base nos valores superiores do ordenamento jurídico: a liberdade, a justiça, a igualdade e o pluralismo político, bem como na dignidade da pessoa, na perspectiva do fenômeno informático. A informática atuando a serviço do homem, e não como restritiva dos direitos fundamentais.

\section{A EVOLUÇÃO DAS LEGISLAÇÕES}

A relação entre o direito à intimidade e a informática também apresenta um lado negativo e um positivo. O primeiro se configuraria com relação ao resguardo geral dos dados e, em particular, dos dados sensíveis. Já o segundo se caracteriza pelo direito de acesso aos dados e pelo direito ao esquecimento. Este último é cada vez mais difícil de ocorrer, devido ao armazenamento dos dados por longos períodos, por isso a necessidade de fixar na legislação um período pelo qual os dados podem ser mantidos. 
A Carta de $\mathrm{Nice}^{27}$ estabeleceu no art. $7^{\circ}$ o respeito pela vida privada e familiar e no art. $8^{\circ}$ a proteção dos dados pessoais. Tal chancelou o caráter autônomo à proteção dos dados pessoais, que passou a não ser visto somente, como uma nova forma de lesão à intimidade. A incógnita era aguardar, para constatar, se tal avanço seria mantido em posterior convenção internacional.

Recentemente, o Tratado de Lisboa ${ }^{28}$ instituiu a Comunidade Européia com a adesão de 27 Estados (em alteração ao Tratado da União Européia) e consolidou a Carta dos Direitos Fundamentais dos países comunitários ${ }^{29}$; Considerando-se que 25 dos países aderiram é amplamente majoritária a vitória do novo direito fundamental, que tutela a proteção dos dados pessoais, previsto no art. 16-B do Tratado. ${ }^{30}$

Assim, o direito fundamental à proteção de dados pessoais logrou se configurar como um direito autônomo. Antes, porém, que chegasse a este patamar ocorreu uma evolução legislativa, de forma diversa em cada país. Em alguns, a tutela se estabeleceu a nível constitucional, outros por meio de lei ou da jurisprudência. No tocante à legislação européia ${ }^{31}$, podem ser caracterizadas três gerações, em uma análise das quatro últimas décadas.

A fase inicial, que se caracteriza pelo rigor na criação dos arquivos informatizados. A lei do Land Hesse, na Alemanha é a primeira, inaugurando a proteção dos dados informatizados de 7/10/70. Este texto pioneiro contemplava somente os arquivos informatizados de titularidade pública. A lei da República Federal Alemã de 27/1/77, que posteriormente a sucedeu, passou a regular os arquivos de titularidade pública e privada. Neste período, foram editadas: a lei sueca de 11/5/73, a lei dinamarquesa de 18/6/78 e a lei austríaca de 18/10/78, que já é de transição.

A segunda fase se caracteriza por normas menos rigorosas para criação de arquivos e pela preocupação com relação à tutela dos direitos fundamentais. São exemplos deste período: a lei francesa de 6/1/78, a lei suíça de 1981 , a lei da Islândia de 26/5/81 e a de Luxemburgo de 30/3/79.

A legislação francesa aporta uma contribuição importante para o âmbito jurídico de proteção de arquivos informatizados, que é a criação da Agência Nacional para proteção de dados. O objetivo do organismo de controle é garantir a segurança e o resguardo da informação pessoal.

O Convênio de Estrasburgo de 28/1/81, marca a terceira fase, que se caracteriza pela unificação do direito europeu. O objetivo é a garantia dos direitos e a tentativa de não obstaculizar o desenvolvimento do setor informático. São deste período a lei do Reino Unido de 12/7/84, a nova lei alemã de 20/12/90, a primeira lei de Portugal de 20/4/91, modificada pela de 26/10/98, a lei espanhola de $31 / 10 / 92$, revogada pela de 13/12/99, bem com a lei italiana de 31/12/96.

Uma contribuição importante que ocorreu a partir da jurisprudência veio da Alemanha, devido à anulação parcial da Lei de Censo da população de 1982, por 
decisão do Tribunal Constitucional, em virtude da sentença de 25/12/83. ${ }^{32}$ O Tribunal extrai do direito fundamental do livre desenvolvimento da personalidade, a faculdade de cada indivíduo de dispor principalmente sobre a revelação e o uso de seus dados pessoais. Para a proteção em função da autodeterminação informativa. $^{33}$ Inicia-se, então, um trabalho para aperfeiçoar a lei federal de proteção de dados, aprovada em 20/12/90. A concepção básica da lei não modificou com relação a legislação de 1977. A mudança substancial que a lei aporta, com relação à anterior é a que se refere ao bem protegido. Estatui como fim o objeto legal, o de proteger os dados pessoais contra os abusos a que pudesse dar lugar o armazenamento, cessão, modificação e eliminação dos dados, visando impedir assim toda a lesão aos interesses legítimos das pessoas.

A terceira geração se caracteriza, ainda, por alguns Estados preverem na Constituição esta matéria e pela perspectiva de direito unificado. Atualmente, a última grande novidade em termos de direito comunitário é a Diretiva 95/46, de 24/10, que além da unificação dos grandes rumos da legislação de dados informatizados na Europa, tenta possibilitar a livre circulação dos mesmos, especialmente no âmbito da Comunidade Européia.

A lei portuguesa a respeito da proteção de dados é a Lei $n .067 / 98$, que transpôs para o ordenamento jurídico português a Diretiva 95/46, a disciplina referente à proteção dos dados pessoais.

$\mathrm{Na}$ Espanha, a previsão normativa começa com o art. $18.4 \mathrm{CE} \cdot{ }^{34} \mathrm{~A}$ Constituição espanhola, junto com a portuguesa ${ }^{35}$ são as Constituições mais recentes $^{36}$ da Europa ocidental, que estão atentas a essa problemática. A Espanha, visando adequar-se ao comando da Diretiva Comunitária editou a Lei Orgânica de Proteção de dados - LOPD (Lei n. -15 , de 13/12/99). A principal novidade que traz a nova lei espanhola é a ampliação de seu objeto, que até então vinha restrito à proteção da honra e intimidade pessoal e familiar dos cidadãos, diante do tratamento de seus dados. A inovação ocorre em duplo aspecto: a) incluem-se no âmbito de proteção da lei todos os bancos de dados, informatizados ou não. Esta é a principal obrigação derivada da Diretiva Comunitária que deveria ser objeto de transposição no direito interno, ao estender a proteção aos arquivos não informatizados; b) protege-se o tratamento de dados pessoais, agora, com relação ao conjunto de liberdades públicas e direitos fundamentais das pessoas, embora permaneça a especial ênfase no âmbito da intimidade.

Na Itália, após a edição da Diretiva foi promulgada a Lei ํo 675, de 31/12/96. O estatuto legal italiano não pretende somente se adequar aos rumos da legislação européia. A pessoa, seja com a titularidade singular ou coletiva, é colocada no centro do ordenamento e é provida de uma garantia específica no setor da informação, que atualmente é o setor mais dinâmico e de maior desenvolvimento na sociedade. O texto legislativo contém duas formas de proteção. Uma para o setor público e outra para o privado. $\mathrm{O}$ aspecto público concerne à liberdade de iniciativa econômica e ao bom funcionamento da Administração com a proteção dos direitos dos administrados. Com relação à pessoa, considerada em sua 
dimensão individual ou coletiva a legislação prevê: direito à intimidade e à identidade pessoal, respeito à liberdade fundamental e respeito à dignidade humana. Esta nova legislação é estreitamente relacionada com os novos caracteres da sociedade informatizada.

Desta maneira, o direito comunitário evoluiu no sentido da Diretiva Comunitária e rumo à Constituição Européia, assinalando nitidamente a unificação das disposições jurídicas.

\section{A EFICÁCIA HORIZONTAL E O DIREITO À INTIMIDADE}

Inicialmente, a Constituição somente limitava os poderes do Estado, por isso a importância em atribuir eficácia aos dispositivos constitucionais. Assim, a grande novidade consistiu em que o cidadão pudesse opor direitos contra o Estado, o que se denomina eficácia vertical. Em contraposição, as relações modernas costumam acontecer muito mais na denominada esfera privada ${ }^{37}$, ou seja, do indivíduo com relação a grupos, o que se reconhece como eficácia horizontal.

Os conflitos não mais se situam na polaridade Estado $x$ cidadão ${ }^{38}$, mas nas relações grupo $\mathrm{x}$ indivíduo. Isso ocorre porque alguns grupos econômicos possuem poder paralelo ao Estado, decorrente, em alguns casos, das privatizações, em que muitos serviços públicos são prestados por empresas privadas. O desenvolvimento da drittwirkung ${ }^{39}$, também conhecida por eficácia diante de terceiros ou eficácia horizontal, é hoje questão principal nos direitos do indivíduo. Os litígios foram progressivamente se deslocando do plano das relações públicas para o das privadas.

É necessário fazer uma crítica à expressão eficácia horizontal, pois, apesar de as relações situarem-se na esfera privada, não estão necessariamente na mesma categoria. Um exemplo disso é uma grande empresa e os trabalhadores ou as instituições financeiras e seus clientes, sendo que ambos podem afrontar o direito à intimidade com seus arquivos. $O$ desenvolvimento da eficácia horizontal se constitui numa normatividade jurídica que tenta compensar as desigualdades fundamentais. Nessa conjuntura, um novo desafio está proposto ao jurista, pois, uma vez que as relações se tornaram mais complexas e dissimuladas, o poder tende a assumir muitas faces.

Claphan utiliza a expressão "privatização dos direitos fundamentais" retomando a Constituição como norma na qual se assenta a unidade do ordenamento jurídico e agregando a influência do direito privado. A Constituição se converte em elemento de unidade e integração do ordenamento jurídico, no dizer de Smend. ${ }^{41}$

A antiga distinção público e privado cede diante da tendência atual de privatização. Como conseqüência disso, cada vez mais serviços que eram prestados pelo Estado deixam de ser públicos. As instituições financeiras, além de 
moverem grandes quantias patrimoniais, armazenam grande quantidade de dados, isto é, de informações sobre seus clientes. Esse fenômeno demanda repensar os temas de direito público.

Desse modo, uma leitura tradicional dos direitos fundamentais como direitos oponíveis diante dos poderes públicos deixaria os indivíduos sem a tutela jurídica dos direitos fundamentais na esfera privada. A célebre dicotomia público-privado, que ocorreu no período do Estado Liberal ${ }^{42}$, pode ser um instrumento arbitrário para excluir grupos e pessoas vulneráveis da proteção conferida pelos direitos fundamentais. A filosofia abstencionista do Estado-liberal entra em crise quando a consciência da marginalização se generaliza nos amplos setores populares e se conecta aos problemas de conflitos da sociedade de massa. Como alternativa ao Estado-liberal, surge o Estado-social.

O uso indevido da informática se constitui numa ameaça aos direitos que independe da natureza pública ou privada de quem armazena os dados. Inclusive, é crescente o número de problemas no setor privado ${ }^{43}$. É possível apontar alguns setores potencialmente conflitivos nesse âmbito, como entidades financeiras e de crédito, companhias de seguro e de segurança privada e empresas de venda e de envio de mala-direta.

Canotilho ${ }^{44}$ aponta para a necessidade de uma resolução diferente destes conflitos. O problema da eficácia dos direitos, liberdades e garantias na ordem jurídica é no sentido da superação da dicotomia eficácia mediata ou imediata em prol de soluções que levem em conta: a função de proteção dos direitos fundamentais, ou seja, as normas que consagram direitos, liberdades e garantias e direitos análogos indicam os princípios de ordenação objetiva, em especial, deveres de garantia e de proteção do Estado, que são eficazes na ordem jurídica privada; b) a necessidade de se considerar a pluralidade de funções dos direitos fundamentais, de maneira a possibilitar soluções distintas, conforme o direito fundamental que esteja em causa; c) a proposição de que a eficácia imediata com relação às entidades privadas dos direitos fundamentais não pretende que os titulares dos direitos, localizados numa posição de igualdade nas relações verticais com o Estado, tenham nas relações horizontais, como em princípio são as relações jurídicas civis, a mesma igualdade. ${ }^{45} \mathrm{Na}$ realidade, o que tenta a lei é amenizar a desigualdade demasiada, uma vez que uma grande empresa multinacional e um empregado, ou uma companhia de seguro e um segurado, não estão na mesma posição.

A seguir, estatui uma diferenciação entre eficácia horizontal expressamente consagrada na Constituição; eficácia horizontal que necessita da mediação do legislador no âmbito da ordem jurídica privada; eficácia horizontal imediata e mediação do juiz; poderes privados e eficácia horizontal; e o núcleo irredutível da autonomia pessoal. ${ }^{46}$

O constitucionalista português da Universidade de Coimbra ${ }^{47}$ assinala a utilização da informática do art. 35.2 da CRP como norma que consagra direitos, 
liberdades e garantias, podendo ela mesma estabelecer a eficácia dos direitos na ordem jurídica privada. Como conseqüência disso, aos particulares é facultado, em suas relações com outros sujeitos privados, requererem eficácia imediata às normas constitucionais que expressamente vinculam os atos das entidades submetidas aos direitos fundamentais.

A eficácia imediata é uma leitura possível a partir do art. 9o, "b", da CRP, apesar do teor do art. $35.2^{48}$ da CRP, que remete à definição legal. Destarte, o direito ao acesso dos dados está sem dúvida garantido com as condições do seu exercício, ficando pendente apenas o conceito de dados pessoais na regulamentação legal.

Sintetizando posições a respeito do tema, Bilbao Ubillos (1997, p. 278) reúne as concepções em três classificações: a) as que negam a drittwirkung aos direitos fundamentais ${ }^{49}$, b) as que defendem a eficácia mediata, que pode ser dividida em:b.1) mediação do legislador e b.2) mediação do juiz; c) as que reconhecem a eficácia imediata.

$\mathrm{Na}$ realidade, é problemático definir em que consiste essa obrigação de proteção assumida pelo Estado e qual é seu alcance. A inércia do legislador é de difícil fiscalização judicial ${ }^{50}$, e sua conseqüência ocorre principalmente na esfera política. A questão primordial é que o problema dos direitos fundamentais em relação aos particulares ocorre pelas abstenções de realizações estatais. Responsabilizar o Estado por todas as condutas omissivas ou comissivas não é algo que resolva os problemas. A necessidade de mediação do legislador parece hoje inconteste, pois ninguém discute o papel preferente do legislador democrático na efetividade dos direitos fundamentais.

Com relação aos efeitos no direito constitucional, o TC se manifestou quando ainda não havia o desenvolvimento legislativo. A STC $254 / 93^{51}$ aponta que a ausência de desenvolvimento legislativo (período anterior à edição da LO 5/92 LORTAD) não priva totalmente de eficácia esse direito, que, por força da Constituição, possui um conteúdo mínimo a ser protegido. Os efeitos são em relação aos bancos de dados administrados pelo setor público ${ }^{52}$ e privado. ${ }^{53}$

Bilbao Ubillos ${ }^{54}$ afirma que a doutrina da eficácia mediata que aponta a intervenção do legislador como "condição para reconhecimento do próprio direito nesse plano" nega a eficácia dos direitos fundamentais. A intervenção do legislador não pode ser um trâmite indispensável. A atuação não tem um caráter constitutivo, senão meramente declaratório. O direito fundamental "poderá ser invocado diretamente, em ausência de uma regulação legal, e será possível obter a oportuna satisfação com seus próprios critérios, a partir da ponderação". ${ }^{55}$

Ao juízo de Bilbao Ubillos,

um direito cujo reconhecimento depende do legislador não é um direito fundamental. É um direito de categoria legal, simplesmente. O direito fundamental se define justamente pela indisponibilidade de seu conteúdo 
pelo legislador. [...] Daí que o termo 'eficácia mediata' denote um equívoco. Aqueles que defendem a necessidade de uma mediação legal como uma obrigação para o reconhecimento do direito estão negando, na realidade, a eficácia 'horizontal' dos direitos fundamentais. ${ }^{56}$

Assim, a aplicabilidade é uma conseqüência do direito fundamental. A intervenção do legislador ocorrerá para explicitar o conteúdo da regra. O legislador, obviamente, não pode prever tudo, e os critérios e a ponderação serão estabelecidos pelo Poder Judiciário. Isso transcende à questão dos direitos fundamentais e sua eficácia com relação a terceiros.

No direito brasileiro não existe artigo similar ${ }^{57}$ ao da Constituição Portuguesa. $\mathrm{O}$ art. 5o, LXII, CF regula a concessão de habeas-data, e a intimidade encontra

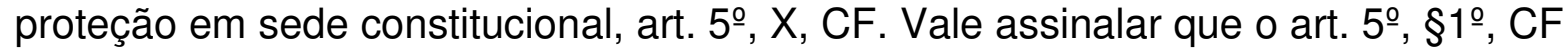
dispõe que as normas definidoras de direitos e garantias fundamentais têm aplicação imediata.

\section{OS DADOS SENSÍVEIS E O PRINCÍPIO DA IGUALDADE}

Um dos fatos que diferenciam o direito das demais áreas do conhecimento é o de que as declarações, quando registradas, ficam vinculadas ao cidadão que as proferiu. Já não se podem promover alterações tão livremente, o dado está "posto" 58 , na medida em que a informação é armazenada no cadastro de um computador. Quando se elaboram as leis no plano normativo, isso é fruto de uma exigência social e, como tal, é dotado de um conteúdo genérico e com força de sanção. Dessa maneira, os critérios de identificação da pessoa devem ser respeitados (seja no âmbito físico, social ou ideal). A finalidade da ordem jurídica, in casu, é defender os direitos da pessoa, ou seja, tutelar sua identidade.

A construção jurídica da identidade pessoal se desenvolve a partir dos direitos surgidos com a Revolução Francesa até nossos dias. Os direitos são portadores de tutela de valores e não configuram a identidade ideal mediante proteção jurídica no âmbito singular e coletivo. Dessa forma, a lei não garante a intimidade no sentido ideal, somente no real.

Os dados de caráter pessoal ${ }^{59}$ contêm informação das pessoas físicas que permitem sua identificação no momento ou posteriormente. $\mathrm{Na}$ sociedade tecnológica, os cadastros armazenam alguns dados que possuem um conteúdo especial, e por isso são denominados dados sensíveis. ${ }^{60}$ Tais dados podem referirse a questões como ideologia, religião ou crença, origem racial, saúde ou vida sexual. Exige-se que os cadastros que os armazenam contenham uma segurança especial, como forma de evitar que sejam mal utilizados.

Com as cautelas especiais relativas aos dados sensíveis, seja quando são recolhidos ${ }^{61}$, seja quanto à segurança ${ }^{62}$ em seu armazenamento, tenta-se garantir que os mesmos não sejam utilizados para outra finalidade ou de maneira 
equivocada.

O dado pessoal é uma informação que permite identificar uma pessoa de maneira direta. A proteção do dado sensível tenta prevenir ou eliminar discriminações. Pode-se dizer que é uma nova leitura do princípio da igualdade ${ }^{63}$, e sua intenção é a de que os dados armazenados não sirvam para prejudicar as pessoas.

Uma das formas prejudiciais de utilização de informações seria o caso em que um banco de dados que contém dados sobre a religião, sexo ou saúde os concedesse a determinada empresa e assim criasse uma situação de desigualdade. Um exemplo disso seria a hipótese de um trabalhador de determinada religião que não pode, em virtude de suas crenças, trabalhar no sábado. Apesar de poder acomodá-lo em outra jornada de trabalho, como forma de garantir seu direito fundamental de liberdade religiosa ${ }^{64}$, a empresa, conhecendo esse dado de forma antecipada, pode deixar de contratá-lo, admitindo outro trabalhador que não traga essa espécie de problema. No que se refere à saúde, um portador do vírus HIV pode não ser contratado em virtude da doença ou ser despedido. A possibilidade de a empresa escolher um trabalhador sadio, no momento da contratação, é muito grande, o que caracterizaria uma discriminação.

Por isso, salvo em um número restrito de atividades profissionais pode ser pedido o exame HIV, ou seja, aqueles em que o empregado realiza uma atividade que se for portador da enfermidade pode causar um contágio. Há de se ponderar a proteção individual do trabalhador com o perigo de expor a saúde da coletividade. Por este motivo é que o Conselho Nacional de Ética para as Ciências da Vida em Portugal considera necessária a realização de testes de HIV para manipuladores de líquidos biológicos, doadores de sangue, doadores de esperma e doadores de tecidos ou órgãos. ${ }^{65}$

Portanto, a divulgação de dados sensíveis pode ocasionar situações de discriminação e prejuízos às pessoas. Desse modo, o princípio da igualdade pode ser vinculado aos dados sensíveis, buscando-se uma maior proteção tanto na sua coleta como na guarda ou na utilização para os fins aos quais foram captados, evitando-se, assim, situações de desigualdade.

\section{O CONTEXTO LATINO-AMERICANO DE PROTEÇÃO DE DADOS}

A América Latina começa a dar os primeiros passos no tema da proteção de dados. Importante documento firmado no âmbito ibero-americano constitui-se na XIII Cumbre, celebrada em Santa Cruz de la Sierra, na Bolívia, nos dias 14 e 15 de novembro de 2003, na qual se reconheceu de forma expressa a importância do direito fundamental à proteção de dados.

Somos conscientes de que a proteção de dados pessoais é um direito fundamental das pessoas e destacamos a importância das iniciativas reguladoras 
ibero-americanas para proteger a privacidade dos cidadãos contidas na Declaração de Antigua, pela qual se cria a Rede Americana de Proteção de Dados, aberta a todos os países de nossa Comunidade.

Tal pacto internacional é uma referência para o desenvolvimento da matéria nos países da América Latina. A Argentina foi o país pioneiro na elaboração legislativa referente ao tema de proteção de dados, por meio da Lei oㅜ 25.326, de outubro de 2000, posteriormente regulamentada pelo Decreto $\mathrm{n}^{0} \mathbf{1 . 5 5 8}$, de novembro de 2001. Essa lei contém o objeto de proteção dos dados pessoais no âmbito público e privado e as definições referentes a dados pessoais, dados sensíveis, armazenamento e tratamento de dados informatizados, titular e usuário dos dados e dissociação dos dados. Versa a respeito de questões polêmicas como consentimento do titular quanto ao repasse dos dados, direito de informação sobre o uso desses dados e distinção entre dados sensíveis e não sensíveis, bem como prevê um órgão de controle dos dados: a Agência de Proteção de Dados. As sanções administrativas estão definidas genericamente na lei e são pormenorizadas pelo Decreto.

No Brasil não há previsão constitucional específica, à semelhança do que ocorre na Espanha e Portugal. No entanto, a partir de dispositivos constitucionais, é possível construir alguma proteção legal, como o habeas-data (art. 5은. LXII); a proteção à intimidade e vida privada (art. $5^{\circ} \mathrm{X}$ ), a inviolabilidade das comunicações (art. 5 XII) e a proteção ao consumidor (art. 5ํ, XXXII, CF). Não obstante, algumas leis setoriais regulamentam a matéria, tais como a Lei $n^{\circ}$ 9.507/97, que disciplina 0 habeas-data, e as Leis n. $.9 .296 / 96$ e $n . .910 .217 / 01$, que dispõem sobre a interceptação telefônica e a gravação ambiental e que tratam também dos dados aí envolvidos. Há ainda a Lei no 8.078/90 (Código de Defesa do Consumidor - CDC) que, em seus arts. 43/4, dispõe sobre os banco de dados nas relações de consumo; a Lei Complementar $n . .9105 / 01$, que permite que autoridades administrativas quebrem o sigilo bancário, na hipótese de delito grave, sem autorização judicial; a Lei $n .0$ 9.613/98, referente à lavagem de dinheiro; e o novo Código Civil (Lei n.. 10.406/02), que, em seus artigos 11/21, dispõe sobre direitos de personalidade.

A maior tutela a respeito da proteção de dados no direito brasileiro tem ocorrido nos bancos de dados com informações de inadimplência dos consumidores. Assim, o consumidor, quando seu nome vai integrar um banco de dados negativo tem o direito de ser notificado (art.43, § 2․, CDC) independente de ser devedor ou não. Quando inexiste esta comunicação, entende-se que ficou configurado o dano moral por ofensa à intimidade, sendo a responsabilidade do responsável pelo arquivo ${ }^{66}$, prioritariamente. Isto é significativo, pois a SERASA ${ }^{67}$ que é um dos grandes bancos de dados atende há mais de 3 milhões de consultas por dia. Assim, tem-se uma idéia da potencialidade do dano de uma informação, que por vezes pode estar equivocada ou desatualizada. 


\section{CONCLUSÕES}

A informática provocou mudanças de costumes na humanidade. Suscita, por isso, novas questões com relação à proteção dos direitos fundamentais, e neste contexto, com a intimidade.

Os bancos de dados contém informações que traduzem aspectos da personalidade, que permitem traçar um perfil do consumidor. Estas informações são uma nova mercadoria com interesse comercial. É necessário, por essa razão, proteger o cidadão juridicamente com relação aos avanços da tecnologia, que pode ter sua intimidade violada, caso os dados sejam divulgados ou utilizados indevidamente.

É essencial o aprimoramento da tutela jurídica, com o objetivo de proteger o cidadão contra os ataques que a informática pode causar na intimidade do cidadão. Deve-se considerar, por conseguinte, as legislações estrangeiras que já estão atentas à problemática há mais tempo, sem deixar de sopesar as características próprias da realidade de cada país.

Pode-se, concluir que a tutela dos direitos da pessoa deve ser compatibilizada com as exigências do mundo atual, que almeja a liberdade de informação e a livre circulação dos dados. Em última análise, a informática é algo que já se incorporou na vida quotidiana moderna. Hoje, não se vislumbra retrocesso. O desafio é como proteger os dados informatizados frente a uma sociedade e um mercado cada vez mais livres de fronteiras. A globalização pressupõe e propõe uma economia sem fronteiras e sem regulamentação. No entanto, não se pode desprezar anos de construção de direitos fundamentais e mudar tudo isso por uma única lei: a lei de mercado e a ilusão de que o mercado tudo regulará. O grande desafio que se impõe no plano dos direitos fundamentais é como fazer com que não somente o capital e os bens de consumo circulem em todo o mundo, mas também os direitos.

O Tratado de Lisboa pôs fim à discussão jurídica, a respeito da autonomia do direito à proteção dos dados pessoais, porém é inconteste que é preciso algo mais além da positivação, é necessária a sua efetividade. É importante, também ir além e propiciar que os países fora do âmbito comunitário elaborem leis de proteção de dados, pois toda a legislação, além da proteção intrínseca que traz em si mesma aos direitos, com a possibilidade de aplicação, contém o aspecto pedagógico, no sentido de despertar que os dados pessoais têm uma importância na sociedade atual. Neste contexto, além de assegurar os direitos dos cidadãos, ao oferecer nível adequado à proteção de dados, o país integra-se nas relações comerciais internacionais. 


\title{
THE EVOLUTION OF THE RIGHT TO BE LEFT IN PEACE TO THE PROTECTION OF THE PERSONAL INFORMATION
}

\begin{abstract}
The computer science phenomenon allows the personal information to flow without boundaries. In this context, the improper use of computers could become in a threat to the right of the privacy, considering the possibility of breaking, spreading and commercialization of the personal information (which is commercialized as new product). It is important to not only assure protection to the rights in the public field, but overall in the private scope, once in today's days, the legal relationships, mainly, are placed in this field. This problematic receives attention from Spain and Portugal, which, in constitutional thirst, they create specific bills to regulate the issue. Recently, the Lisbon Agreement recognized the protection of personal information as fundamental rights. In Brazil, it is necessary to elaborate specific legislation, while this does not take place, but it is possible to construct legal protection, from the Constitution. Currently, the great challenge, in the globalized world, is to protect the privacy of the citizens concerned to Electronic Data Interchange.
\end{abstract}

Keywords: Computer Science. Constitution. Fundamental Rights. Globalization. Protection of Personal Information.

\section{NOTAS}

Doutora em Direito (Universidade Pompeo Fabra, Barcelona - Espanha). Professora da disciplina Estado e Administração junto ao PPG Unisinos. Promotora de Justiça/RS.

1 ORTUÑO, Mercedes. El papel de la Agencia Española de protección de datos en la lucha contra el "spam". Disponível em: <www. agpd.es >. Acesso em:26 mai 2008.

2 ORWELL, George. 1984. 29. ed. São Paulo: Companhia Editora Nacional, 2003.

3 BOBBIO, Norberto. A era dos direitos. Rio de Janeiro: Campus, 1992, p. 24.

4 Sentença de 15/12/83, do TC Alemão, BCJ, 1984, p.137

5 O problema dos dados interativos é que, depois de armazenados, o sujeito tende a esquecer que os forneceu. ZENO ZENCOVICH, Vicenzo. I nuovi sistemi telematici interattivi e la tutela del diritto all'identità personales, QDC, In: Banche Dati Telematica e Diritti della Persona, CEDAM, Padova, 1984.

6 Com relação ao tratamento dos dados pessoais e a proteção da intimidade no setor das telecomunicações, a DC 97/66, de 15/12/97, é complementar à DC 95/46. Protege, inclusive, os interesses das pessoas jurídicas.

7 D’ÁVILA, Sérgio. Big Brother EUA. Folha de São Paulo, São Paulo, p. A23, 16 jun. 2002.

8 Loja Once Famous, em Mineapolis (Estado de Minnesota).

$9 \quad$ D’ÁVILA, Sérgio. Big Brother EUA. Folha de São Paulo, São Paulo, p. A23, 16 jun. 2002.

10 Nos bancos de dados com registro negativo, o controle do consumidor inadimplente é feito por números, qual seja por meio do n. do CPF. BESSA, Leonardo Roscoe. O consumidor e os limites dos bancos de dados de proteção ao crédito. São Paulo: RT, 2003.

11 Constituição Portuguesa, art. 103, § 2º, CF e art. 283. 
12 Constituição Brasileira, art. 5, X e o direito à informação, art. 5ำ, XXXIII, que foi regulamentado pela Lei no . 9.507/97, que disciplina o habeas-data. Constiuição Espanhola, art. 18.4 e art. 105, "b".

13 O número 7 do art. 35, aditado pela Revisão constitucional de 1997, estatui: "Os dados pessoais constantes de ficheiros manuais gozam de proteção idêntica à prevista nos números anteriores, nos termos da lei".

14 SARMENTO E CASTRO, Catarina. Direito da Informática, privacidade e dados pessoais. Coimbra: Almedina, 2005, p. 33.

15 A relação do art. 105, "b", e do art. 18.4 da CE frente ao art. 20.1, "d".

16 PÉREZ LUÑO também aponta para o caráter objetivo-institucional dos direitos fundamentais, que vai além do sentido clássico. Os direitos humanos como "um conjunto de faculdades e instituições que, em cada momento histórico, concretizam as exigências de dignidade, liberdade e igualdade humana, as quais devem ser reconhecidas positivamente pelos ordenamentos jurídicos." PÉREZ LUÑO, Antonio. Derechos humanos, Estado de derecho y constitución. 8. ed. Madrid: Tecnos, 2003, p. 48.

17' BAÑO LEON, Jose Maria. "La distinción entre direito fundamental y garantía institucional en la Constituión Española". REDC, Madrid, ano 8, $\mathrm{n}^{\circ}$. 24, sep./dic. 1988, p. 159. Häberle afirma, também, que o legislador tem um papel ativo importante para assegurar o conteúdo e, posteriormente, a efetividade dos direitos fundamentais. É a proposição de Häberle do status activus processuali, qual seja, a participação do indivíduo no Estado Constitucional, sem separar direito fundamental e garantia. (HÄBERLE, Peter. Le libertà fondamentali nello Stato Constituzionale. Roma: La Nuova Italia Scientifica, 1996). Para Carl Scmitt a distinção entre direito e garantia é obrigatória. (SCHMITT, Carl. Teoría de la Constitución. Madrid: Alianza, 1996, p. 45-57).

18 O direito à intimidade, the right to privacy, surgiu por criação de Samuel Warren e Louis D. Brandeis, sendo que este último, posteriormente, foi juiz da Suprema Corte. O Senador Samuel Warren considerou que a imprensa de Boston tinha exagerado ao divulgar notícias reservadas sobre o matrimônio da sua filha. Warren pediu ajuda ao jurista Brandeis, a fim de verificar se o common law oferecia uma norma para proteger a intimidade do cidadão. A partir da análise dos precedentes, documentou-se o reconhecimento na common law de um direito geral à privacy, reconstruído por meio dos casos de violação de propriedade (property), violações da confiança (breach of confidence), violações do direito de autor (copyright) e também dos casos de difamação (defamation). A conclusão a que chegaram foi de que, através do direito geral à privacy, era possível obter uma proteção jurídica também no caso de a violação da vida privada ocorrer por meio da imprensa. As conclusões foram publicadas num artigo em 1890. A doutrina de Warren e Brandeis parte dos clássicos direitos de liberdade e propriedade para defender o direito a ser deixado em paz. Dessa maneira, o direito à liberdade assegura direitos civis, e o direito à propriedade assegura toda forma de posse, de conteúdo material ou não. Partindo do direito de propriedade, surgem o direito de propriedade intelectual e criação artística, cada vez com conteúdo mais imaterial, até chegar à privacy, como um direito autônomo. Partiu-se da privacy-property, que se configurava como uma relação entre o particular e sua vida privada, e, em conseqüência, com a faculdade de fazer públicas certas manifestações quando se entende oportuno. A privacy se via atacada somente naqueles casos em que um estranho entrava no círculo de confiança de outra pessoa. A vulnerabilidade era verificada somente por meio de intromissões físicas. Posteriormente, a privacy se associou com a idéia de liberdade, configurando-se a inviolabilidade da personalidade humana.

19 Georg Jellinek estruturou os elementos do Estado, levando em conta, o típico do Século XIX: povo, território e poder (soberano). Com o advento do fenômeno informático, onde se pode fazer com que os dados se desloquem de um país ou continente a outro, isso provoca mudança em todos os referenciais com relação ao território, e o mesmo ocorre com relação à soberania, vide o fenômeno da Comunidade Européia. JELLINEK, Georg. Teoría General del Estado. 2. ed. [reimp. de la segunda edición alemana (1905) editada por el Ed. Albatros en el año 1954]. Buenos Aires: Julio César Faira, 2005, p. 495-625.

20 Em outra perspectiva o MERCOSUL é de grande importância para o sul da América Latina. México, Estados Unidos e Canadá constituíram uma espécie de mercado comum conhecido 
como NAFTA (em inglês) ou ALENA (Associação de livre intercâmbio da América do Norte). Esses são exemplos de supranacionalidade.

21 Por vezes, a palavra "globalização" é preferida pelos economistas e cientistas políticos, enquanto a "pós-modernidade" o é pelos filósofos e sociólogos. André-Jean Arnaud aponta para as principais características da modernidade: abstração, subjetivismo, universalismo, unidade da razão, axiomatização, simplicidade, o contraponto sociedade civil e Estado e segurança. Em contraposição, na pós-modernidade: pragmatismo, descentralização do sujeito, relativismo, pluralidade de racionalidades, lógicas partidas, complexidade, retorno da sociedade civil e risco. O pós-moderno é o que se segue ao moderno (período do pensamento ocidental nos séculos XVI a XVIII). Assim, para Arnaud, a pós-modernidade no direito se caracteriza por uma superação dialética do paradigma "moderno" estruturado a partir da abstração, axiomatização, subjetivismo, simplicidade e segurança nas relações jurídicas, separação da sociedade civil e do Estado, universalismo e unidade da racionalidade jurídica. ARNAUD, André-Jean. O Direito entre a modernidade e a globalização: lições de filosofia do Direito e do Estado. Rio de Janeiro, Renovar, 1999, p. 203.

22 HÄBERLE, Peter. Pluralismo y Constitución. Madrid: Tecnos, 2002, p.15.

${ }_{23}$ É o que os alemães denominam de o "retorno Kantiano", (HÖFFE apud TORRES, Ricardo Lobo. O orçamento na Constituição. Rio de Janeiro: Renovar, 1995, p. 90).

24 STRECK, Lênio. Jurisdição Constitucional e Hermenêutica: uma nova crítica do direito. 2. ed., Rio de Janeiro: Forense, 2004, p. 870-871.

25 CANOTILHO, José Joaquim Gomes. Fundamentos da Constituição. Coimbra: Coimbra Ed., 1991, p. 99.

26 SARLET diz, a respeito da dignidade da pessoa humana, "sem que se reconheçam à pessoa humana os direitos fundamentais que the são inerentes, em verdade estar-se-á lhe negando a própria dignidade". SARLET, Ingo Wolfang. Dignidade da pessoa humana e direitos fundamentais na Constituição de 1988. 3. ed. rev. atual. ampl. Porto Alegre: Livraria do Advogado, 2004, p. 86.

27 Firmada em 7 de dezembro de 2000.

28 Firmado no dia 13/12/2007, no Mosteiro dos Jerônimos.

29 Com exceção da reserva posta, relativa a alguns dispositivos que instituem direitos, pelo Reino Unido e Polônia, do qual se inclui, especificamente, a proteção dos dados pessoais.

30 Publicação no Jornal Oficial da União Européia, publicado em 17/12/2007.

31 Importante referir também a experiência nos EUA: o Freedom of Information Act (1974) e o Freedom of Information Reform Act (1986), que visam assegurar o acesso e à retificação ou complementação das informações . No direito norte-americano a preocupação se centra nos dados armazenados na administração pública. Estima-se que aí estão cerca de $50 \%$ dos dados informatizados do mundo (GELLMAN, Robert. "Les trois piliers de la politique de diffusion de l'information publique aux États-Units", Revue française d'administration publique, n. -72 , octobre-décembre 1994 , p. 602 . Por isso, evidentemente merece preocupação os bancos de dados públicos, pela quantidade de informação armazenada nos EUA.

32 Boletín de Jurisprudencia Constitucinal, 1984, p. 137

33 "A autodeterminação informativa é entendida como controlo sobre informação relativa à pessoa. Consiste no interesse em impedir ou em controlar a tomada de conhecimento, a divulgação ou, simplesmente, a circulação de informação sobre a pessoa, isto é, sobre factos, comunicações ou situações relativo (sic) (ou próximos) ao indivíduo, e que previsivelmente ele considere como íntimos, confidenciais ou reservados". MOTA PINTO, Paulo Cardoso Correia da. A proteção da vida privada. Boletim da Faculdade de Direito, vol. LXXVI, Universidade de Coimbra, 2000, p. 164.

34 O art. 18.4, da CE dispõe: "A lei limitará o uso da informática para garantir a honra e a intimidade pessoal e familiar dos cidadãos e o pleno exercício dos direitos ".

35 A Constituição portuguesa, em seu artigo $3^{\circ}$, disciplina a utilização da informática e em seu artigo 26, diz respeito a outros direitos pessoais, entre eles a reserva da intimidade da vida privada e familiar.

O artigo 35 refere a utilização da informática.

36 Costuma-se estabelecer como marco as Constituições do segundo pós-guerra. Assim, na Alemanha, a Lei Fundamental de Bonn de 1949, as Constituições Francesa de 1958 e a 
Italiana de 1947, todas elas ainda em vigor . Estas Constituições vão influenciar a mudança das Cartas, após a queda de Salazar e Franco com a mudança dos regimes políticos. Tal exigiu a elaboração de novas Constituições em Portugal e na Espanha. Estas, por sua vez, influenciaram o modelo brasileiro na Constituição de 1988.

37 Apesar de a contraposição do público com relação ao privado ser típica do Liberalismo e cada vez mais ocorrer o fenômeno a que se denomina de publicização do privado, serve para exprimir a idéia das relações que se dão entre os particulares.

38 No dizer de Natalino Irti: "O Código Civil perdeu, por um lado, todo valor 'constitucional': as liberdades políticas e civis, o direito da propriedade, a iniciativa privada econômica recebem hoje a tutela da Constituição, isto é, das normas hierarquicamente superiores." IRTI, Natalino. La edad de la descodificación. Barcelona: Bosch, 1992, p. 35.(N.T.: Tradução livre da tradutora. Vide original na bibliografia.)

${ }^{39}$ Não obstante a eficácia dos direitos fundamentais terem se desenvolvido a partir da década de 1950, isso não é uma total novidade na história constitucional. A declaração dos direitos do homem de 1789 não afirmava somente o valor dos direitos fundamentais com relação ao Estado. Conduzia-se também contra os privilégios da nobreza e do clero, contra as posições desiguais em virtude da classe social e do poder econômico no âmbito privado. O Estado deveria assegurar a liberdade no âmbito privado. Somente com a teoria Liberal individualista surgiram duas idéias: a função dos direitos fundamentais é a defesa dos indivíduos com relação ao Estado (direitos de defesa), b) o direito privado possui seu próprio direito, sobretudo códigos, apartado do direito constitucional, no dizer de CANOTILHO, José Joaquim Gomes. Fundamentos da Constituição. Coimbra: Coimbra Ed., 1991, p. 608.

40 Claphan apud UBILLOS, Juán Maria Bilbao. La eficacia de los derechos fundamentales frente a particulares. Madrid, CEC, 1997.

41 SMEND, Rudolf. Constituicón y Derecho Constitucional. Madrid: CEC, 1982, p. 132.

42 A forma liberal de tratar as relações sociais no período liberal são as distinções entre Estado/sociedade, público/privado, indivíduo/grupo, direito/político, objetivo/subjetivo, etc. A grande dicotomia: público e privado. (BOBBIO, Norberto. Estado, governo e Sociedade. 4. ed. São Paulo: Paz e Terra, 1992, p. 33-49).

43 BILBAO UBILLOS, Juan. La eficacia de los derechos fundamentales frente a particulares. Madrid, CEC, 1997, p. 778, (In nota oㅜ 767), relata um fenômeno preocupante das empresas privadas que fazem comércio aberto dos dados pessoais. Inclusive no início de 1992 se descobriu na Espanha uma ampla rede de compra e venda desse tipo de dados informatizados que souberam aproveitar o vazio legal. Empresas comerciais e instituições financeiras solicitam informação acerca da solvência e o grau de cumprimento de morosos ou de condutores com alto índice de sinistralidade (junto às companhias de seguro de carros), são as conhecidas "listas negras". Essas listas circulam sem que os afetados tenham conhecimento delas, mas podem, no entanto, Ihes causar graves prejuízos.

44 Cinco exemplos são colocados, a fim de refletir se estão por incidir normas de direito privado ou constitucional para a resolução do conflito. O primeiro caso é referente a um condomínio nos Estados Unidos no qual se proibiu, no contrato, a venda de imóveis a negros. A cláusula viola a Constituição no princípio da igualdade ou no direito civil por ferir a liberdade contratual? (CANOTILHO, GRAU, Eros Roberto; GUERRA FILHO, Willis Santiago (Org.). Direito Constitucional: estudos em homenagem a Paulo Bonavides. São Paulo: Malheiros, 2001, p. 108-115).

45 Já se fez uma crítica à expressão eficácia horizontal, uma vez que as partes da causa não estão na mesma posição, inexistindo a igualdade.

46 CANOTILHO, José Joaquim Gomes. Direito Constitucional. 5. ed. Coimbra: Almedina, 1992, p. 608-610.

47 Idem, p. 608-609.

48 Art. 35.2. A lei define o conceito de dados pessoais, bem como as condições aplicáveis a seu tratamento automatizado, conexão, transmissão e utilização, e garante sua proteção pela entidade administrativa independente.

49 Nos quais se encontra Ernst Forsthoff, respectivamente citado por BILBAO UBILLOS, "para que os direitos fundamentais possam cumprir uma função social, não é necessário renunciar a sua configuração como limites ao poder do Estado". Forsthoff tem claro que "a liberdade 
significa distanciamento do indivíduo frente ao Estado". Assim, "o mais razoável é manter a função protetora dos direitos fundamentais dentro dos limites de eficácia que desde sempre se Ihes atribuiu, e que permitiu apresentá-los como defesa diante das intervenções soberanas". (UBILLOS, Juán Maria Bilbao. La eficacia de los derechos fundamentales frente a particulares. Madrid, CEC, 1997, p. 278-279). Nessa classificação, com posições um pouco mais distintas, as afirmações de G. Amato, A. Favre, J. F. Aubert, etc. O denominador comum entre os que rechaçam a drittwirkung dos direitos fundamentais é "a ênfase com a qual se denunciam os riscos que essa doutrina entranha para a liberdade contratual e a segurança jurídica. Esses autores chamam a atenção sobre a lógica de liberdade que atravessa o direito civil. Suas normas se apresentam como um modelo de equilíbrio na defesa das liberdades individuais, de modo que a irrupção dos direitos garantidos diretamente pela Constituição neste marco de paz social e liberdade seria perturbadora, produziria 'entrecruzamentos e colisões' e conduziria em última instância a uma 'inflação protetora'". Em síntese, é "a convicção de que a drittwirkung possa ser uma espécie de 'cavalo de tróia' que destruiria o sistema articulado sobre a base da autonomia privada" (UBILLOS, Juán Maria Bilbao. La eficacia de los derechos fundamentales frente a particulares. Madrid, CEC, 1997, p. 283).

50 A Constituição Portuguesa (art. 283) prevê a ação de inconstitucionalidade por omissão quando o Tribunal Constitucional verificar a inércia do legislativo. No entanto, não há fixação de prazo para a adoção das medidas cabíveis, até porque não se pode obrigar o legislativo a legislar. O mesmo ocorre com a Constituição Brasileira, art. 103, § 2º, com uma diferença: tratando-se de cientificação do órgão administrativo, o cumprimento deverá ocorrer em 30 dias, e, no caso do Poder Legislativo, não há prazo.

51 Nessa decisão, reitera-se a doutrina propugnada pela STC 15/82 com respeito à aplicabilidade imediata do direito à objeção de consciência e à direta exigilibilidade, enquanto não se desenvolva o mandato constitucional de um mínimo de conteúdo, que há de ver-se desenvolvido e completado pelo legislador. Nesse caso, os direitos a obter informação exercitados pelo demandante de amparo formam parte, sim, segundo o Tribunal, "do conteúdo mínimo que consagra o art. 18 da CE com eficácia direta" (BILBAO UBILLOS, La eficacia de los derechos fundamentales frente a particulares. Madrid, CEC, 1997, p. 777).

52 Além de incidir no setor público, a lei também incide no privado, como, por exemplo, nas relações de trabalho, nas entidades financeiras e creditícias, nas companhias de seguros e nas empresas comerciais.

53 A experiência norte-americana é no sentido inicial de ocupar-se unicamente do tratamento desses dados nas instituições públicas, a Privacy act de 1974. Posteriormente, foram aprovadas leis setoriais e estatais que se ocupam das entidades privadas (bancos, instituições financeiras, companhias de seguros, etc).

54 Bilbao Ubillos cita o pensamento de J.Jiménez Campo, sustentando que a intervenção do legislador é condição para o reconhecimento do próprio direito neste plano, alheio já às relações jurídico-públicas normatizadas de modo direto pela Constituição". (BILBAO UBILLOS, La eficacia de los derechos fundamentales frente a particulares. Madrid, CEC, 1997, p. 296).

55 BILBAO UBILLOS, La eficacia de los derechos fundamentales frente a particulares. Madrid, CEC, 1997, p. 297.

$56 \quad$ Idem, p.297.

57 Considerando o art. 18.4 da CE e o art. 35.2 da CRP.

58 Em uma analogia ao pensamento de Kelsen, direito posto pelo Estado. Assim, como norma mais elevada, ela tem que ser pressuposta, visto que não pode ser posta por uma autoridade cuja competência teria de se fundar em uma norma ainda mais elevada. (KELSEN, Hans. Teoria pura do direito. São Paulo: Livraria Martins Fontes, 1985, p. 207).

59 Art.3, a da LO 15/99.

60 O art.7 e seus aparelhos da LO 15/99 se ocuparam dos dados especialmente protegidos com uma novidade. O art.16.2, CE somente referia a ideologia, religião e crenças. O art.7.1, da LORTAD reproduzia o mesmo. O art.7.2, da LOPD acrescenta os dados de afiliação sindical.

61 Art. 16.2 da CE e art. 7.2 da LO 15/99, em que se exige o consentimento expresso para o tratamento dos dados de caráter pessoal. A nova lei reforça o consentimento dos cidadãos para que seus dados possam ser tratados. A LORTAD não definia o consentimento, do que agora a LOPD se ocupa, nos arts. 6.1 e 7.2. Assim, o consentimento deverá ser inequívoco 
nos dados de caráter pessoal e expresso e por escrito nos dados especialmente protegidos. Dessa maneira, é possível concluir que o consentimento seja livre, inequívoco, específico e informado. Sobre a necessidade do consentimento expresso, vide STC 202/99.

Sobre a segurança dos cadastros automatizados que contenham dados de caráter pessoal, art.9.2 e art.44.3, "h", da LO 15/99 e, também o Real Decreto 994/99, de 11 de junho.

63 Os princípios básicos do liberalismo são a liberdade e a igualdade. A Revolução Francesa propugna a "igualdade formal", porque estabelece a fórmula genérica de que todos são iguais perante a lei. A evolução do postulado conduz à "igualdade material". Reconhecem-se algumas distinções como forma de estabelecer uma igualdade na vida real. Dessa maneira, podem ser apontadas situações discriminatórias, em virtude do reconhecimento de características próprias, que não violam o princípio da Igualdade. São exemplos dessas situações alguns casos de aposentadoria em tempo distinto, em virtude da profissão, a licença maternidade, que é conferida na maioria dos países somente às mulheres, e a discriminação positiva como forma de melhorar a representação política das mulheres nos Parlamentos.

STC 19/85, de 13/2, que considerou vulnerado o direito fundamental de liberdade religiosa com relação à demissão, uma vez que havia a possibilidade de mudança do regime de descanso semanal.

65 GUERRA, Amadeu. A privacidade no local de trabalho. Coimbra: Almedina, 2004, p. 269.

66 Esta é a posição majoritária do Superior Tribunal de Justiça.

67 SERASA - Centralização de Serviços Bancários S.A, estes dados foram fornecidos pelo departamento jurídico da própria instituição em conferência proferida no I Seminário Internacional de Proteção de Dados, Hotel Transamérica de São Paulo, em 25/11/2005.

\section{REFERÊNCIAS}

ARNAUD, André-Jean. O Direito entre a modernidade e a globalização: lições de filosofia do Direito e do Estado. Rio de Janeiro, Renovar, 1999.

BAÑO LEON, Jose Maria. "La distinción entre direito fundamental y garantía institucional en la Constituión Española". REDC, Madrid, ano 8, $\mathrm{n}^{\circ}$. 24, sep./dic. 1988.

BESSA, Leonardo Roscoe. O consumidor e os limites dos bancos de dados de proteção ao crédito. São Paulo: RT, 2003.

Boletín de Jurisprudencia Constitucional, n.ํ33, enero, 1984.

BOBBIO, Norberto. A era dos direitos. Rio de Janeiro: Campus, 1992.

. Estado, governo e Sociedade. 4. ed. São Paulo: Paz e Terra, 1992.

CANOTILHO, José Joaquim Gomes. Fundamentos da Constituição. Coimbra: Coimbra Ed., 1991.

. Direito Constitucional. 5. ed. Coimbra: Almedina, 1992.

Carta de Nice. Disponível em: < http://europa.eu.int/futurum> Acesso em: 26/05/08.

DÁVILA, Sérgio. Big Brother EUA. Folha de São Paulo, São Paulo, p. A23, 16 jun. 2002. 
GELLMAN, Robert. "Les trois piliers de la politique de diffusion de l'information publique aux États-Units", Revue française d'administration publique, n. ำ 72 , octobre-décembre 1994.

GRAU, Eros Roberto; GUERRA FILHO, Willis Santiago (Org.). Direito Constitucional: estudos em homenagem a Paulo Bonavides. São Paulo: Malheiros, 2001.

GUERRA, Amadeu. A privacidade no local de trabalho. Coimbra: Almedina, 2004.

HÄBERLE, Peter. Le libertà fondamentali nello Stato Constituzionale. Roma: La Nuova Italia Scientifica, 1996. . Pluralismo y Constitución. Madrid: Tecnos, 2002.

IRTI, Natalino. La edad de la descodificación. Barcelona: Bosch, 1992.

JELLINEK, Georg. System der Subjektiven öffentlichen recht, zweite durchgesehene und vermehrte auflage, anastatischer neudruck der ausgabe von 1905. Tübingen: editora, 1919.

. Teoría General del Estado. 2. ed. [reimp. de la segunda edición alemana (1905) editada por el Ed. Albatros en el año 1954]. Buenos Aires: Julio César Faira, 2005.

KELSEN, Hans. Teoria pura do direito. São Paulo: Livraria Martins Fontes, 1985.

MOTA PINTO, Paulo Cardoso Correia da. A proteção da vida privada. Boletim da Faculdade de Direito, vol. LXXVI, Universidade de Coimbra, 2000.

ORTUÑO, Mercedes. El papel de la Agencia Española de protección de datos en la lucha contra el "spam". Disponível em: <www. agpd.es >. Acesso em: 26/5/2008.

ORWELL, George. 1984. 29. ed. São Paulo: Companhia Editora Nacional, 2003.

PÉREZ LUÑO, Antonio. Derechos humanos, Estado de derecho y constitución. 8. ed. Madrid: Tecnos, 2003.

SARLET, Ingo Wolfang. Dignidade da pessoa humana e direitos fundamentais na Constituição de 1988. 3. ed. rev. atual. ampl. Porto Alegre: Livraria do Advogado, 2004.

SARMENTO E CASTRO, Catarina. Direito da Informática, privacidade e dados pessoais. Coimbra: Almedina, 2005.

SCHMITT, Carl. Teoría de la Constitución. Madrid: Alianza, 1996.

SMEND, Rudolf. Constituicón y Derecho Constitucional. Madrid: CEC, 1982.

STRECK, Lênio. Jurisdição Constitucional e Hermenêutica: uma nova crítica do direito. 2. ed., Rio de Janeiro: Forense, 2004.

TORRES, Ricardo Lobo. O orçamento na Constituição. Rio de Janeiro: Renovar, 1995.

UBILLOS, Juán Maria Bilbao. La eficacia de los derechos fundamentales frente a 
particulares. Madrid: CEC, 1997.

Tratado de Lisboa. Disponível em: <http://www.eur-lex.europa.eu > Acesso em: 26 mai 08.

ZENO ZENCOVICH, Vicenzo. I nuovi sistemi telematici interattivi e la tutela del diritto allidentità personales, QDC, In: Banche Dati Telematica e Diritti della Persona, CEDAM, Padova, 1984.

Recebido para publicação 11/112008

Aceito para publicação 13/01/2009 